\title{
OUTCOME OF NON-INVASIVE VENTILATION (NIV) AMONG PATIENTS WITH TYPE II RESPIRATORY FAILURE DUE TO ACUTE EXACERBATION OF CHRONIC OBSTRUCTIVE PULMONARY DISEASE (COPD).
}

1. MBBS, MD, DTCD, FCPS (Pulmonology) Senior Registrar Pulmonology Nishtar Medical University Multan.

2. MBBS, FCPS (Pulmonology) Assistant Professor Pulmonology Chaudhary Pervaiz Elahi Institute of Cardiology Multan

3. MBBS, DTCD, FCPS (Pulmonology) Senior Registrar Pulmonology Nishtar Medical University Multan.

4. MBBS, DTCD, FCPS (Pulmonology) Assistant Professor Pulmonology Nishtar Medical University Multan.

5. MBBS, FCPS (Pulmonology) Assistant Professor Sahiwal Medical College, Sahiwal.

6. MBBS, FCPS (Pulmonology) Consultant Pulmonologist Fatima Jinnah Chest Hospital Quetta.

\section{Correspondence Address:} Dr. Muhammad Atiq UI Mannan Ward no 22, Department of Pulmonology

Nishtar Medical University, Multan. atiq_ul_mannan@yahoo.com

Article received on: 12/09/2019 Accepted for publication: 25/11/2019
Muhammad Atiq ul Mannan', Muhammad Imran Shahzad², Muhammad Waqas Afzal², Humayoun Ghulam Murtaza ${ }^{4}$, Muhammad Waseem ${ }^{5}$, Tahir Khan ${ }^{6}$

ABSTRACT... Objectives: To determine the "frequency of 'success' of non-invasive ventilation (NIV) among patients with type II respiratory failure due to acute exacerbation of chronic obstructive pulmonary disease (COPD)". Study Design: Cross sectional Study. Setting: Department of Pulmonology Nishtar Hospital Multan. Period: March 2016 August 2016. Material \& Methods: A total of 101 study cases meeting inclusion and exclusion criteria of this study were registered using non probability consecutive sampling technique. Arterial samples for arterial blood gases (ABG) were sent. Base line $\mathrm{pH}$ and $\mathrm{pcO} 2$ were measured. All the patients were offered with NIV for 12 hours. After 12 hours, ABG was again measured to see any improvement in $\mathrm{pH}$ and $\mathrm{pCO} 2$. Success as labeled as 'yes' if $\mathrm{pH}>7.35$ and $\mathrm{pCO} 2$ is $<60 \mathrm{~mm}$ of $\mathrm{Hg}$. The patients were discharged and follow up time was adjusted. Results: Out of these 101 study cases, 53 (52.5\%) were male and 48 (47.5\%) were female patients having mean age $61.50 \pm 10.77$ years. Mean duration of disease was $8.54 \pm 5.26$ years. Mean BMI levels of our study cases was $23.31 \pm 2.18 \mathrm{Kg} / \mathrm{m}^{2}$. Mean baseline $\mathrm{pH}$ value was $7.32 \pm 0.016$. Mean baseline $\mathrm{pCO}_{2}$ value was calculated to be $67.56 \pm 6.05 \mathrm{mmHg}$. Mean pH value at 12 hours after NIV was $7.37 \pm 0.02$. Mean $\mathrm{pCO}_{2}$ value at 12 hours after NIV was calculated to be $51.32 \pm 6.30 \mathrm{~mm} \mathrm{Hg}$. Success was achieved in $98(97 \%)$ of our study cases. Success was stratified with regards to gender, age, BMI and duration of disease and $p$ values calculated were found to be $p=1.00$, $p=0.591, p=0.026$ and $p=0.606$ respectively. Conclusion: Our study results indicate that Noninvasive ventilation (NIV) is effective, reliable, safe and very cost effective method among the patients with respiratory failure due to acute exacerbation of COPD.

Key words: $\quad$ Acute Exacerbation, COPD, Non-invasive Ventilation.

Article Citation: Atiq ul Mannan M, Shahzad MI, Afzal MW, Murtaza HG, Waseem M, Khan T. Outcome of non-invasive ventilation (NIV) among patients with type II respiratory failure due to acute exacerbation of chronic obstructive pulmonary disease (COPD). Professional Med J 2020; 27(5):1027-1031. DOI: 10.29309/TPMJ/2020.27.05.4145

\section{INTRODUCTION}

Chronic Obstructive Pulmonary Disease (COPD) is commonly encountered by pulmonologists and physicians worldwide. Typical symptoms of chronic obstructive pulmonary disease (COPD) patients are "chronic bronchitis and emphysema, but the classic triad also includes asthma". Chronic bronchitis may be regarded as persistence of chronic productive cough for duration of more than 3 months during last 2 consecutive years while other reasons of coughing be excluded. Emphysema can be termed pathologically as permanently abnormal enlargement of air spaces which are distal to the terminal bronchioles, associated with destruction of their walls having no typical signs of fibrosis. ${ }^{1}$
Worldwide exact magnitude of the COPD still needs to be elaborated while different estimates have reported varying ranges from $7-19 \%$ in different parts of the world with $10.1 \%$ prevalence rate all over the world as reported by burden of Obstructive Lung Disease (BOLD) study. ${ }^{2}$

Acute exacerbation of COPD is a period for acute deterioration that largely affects the physical health status of COPD and leads to frequent hospital admissions, emergency visits as well as increased rates of mortality. ${ }^{3}$ Different estimates have reported morality rates ranging from 4 to 30 $\%$ in different population subsets, however higher rates of morality have been observed among 
acute respiratory failure (ARF) patients which are associated with increasing age and having co - morbidities (up to $50 \%$ ) while patients who are admitted to intensive care unit (ICU) have mortality rate of $11-26$. $^{4}$

Non-invasive ventilation (NIV) is regarded as employment of artificial ventilation of these patients with no use of tubal access of endotracheal or tracheostomy tube. ${ }^{5}$ These days, NIV has gained a major role in the treatment of patients having acute respiratory failure. NIV helps to prevent different complications related with invasive ventilations such as; airway issues, nosocomial pneumonia up to $21 \%$ and sinusitis which ranges $5-25 \%$ by avoiding endotracheal intubation. ${ }^{6}$

Noninvasive mechanical ventilation may be employed in ICU setting as well as among inpatients by a highly trained team of healthcare professionals effectively and safely to get desired outcomes. ${ }^{7}$ However, NIMV treatment is not globally recommended as per guidelines of the American Thoracic Society (ATS) and the British Thoracic Society (BTS) for every patient presenting with acute respiratory failure. NIMV may not be regarded as an alternate for intubation and invasive mechanical ventilation especially when latter is obviously more appropriate ${ }^{8}$ as NIMV failure rates among respiratory failure patients of COPD has been shown to be $5-40$ $\%{ }^{9}$

In a recent study conducted by Pnadey, et al ${ }^{10}$ in Nepal reported twelve hours after bi-level ventilation, $78.7 \%$ patients had normal $\mathrm{pH}$ and 42.8\% had pCO2 above $60 \mathrm{~mm} \mathrm{Hg}$ showing successful in 27 patients (96.4\%).

Acute exacerbation of COPD is very common in a developing country like Pakistan. The mortality is also very high. For such patients, ideal treatment is mechanical ventilation. However, it is not possible to arrange ICU care for every patient with acute exacerbation of COPD. Previously, Pnadey et al, have shown promising results with NIV among such patients. However, this is the only study which have shown a success rate of $>90 \%$. This study was conducted only in a limited sample size of 28 patients. Therefore results cannot be generalized on such population hence this study was designed with adequate sample size and if success is found to be high then same modality would be used in such patients in future.

\section{MATERIAL \& METHODS}

One hundred and one patients with type II respiratory failure due to acute exacerbation COPD were registered through department of Pulmonology, Nishtar Medical University, Multan in this descriptive case series. All the patients with acute exacerbation of COPD leading to type II respiratory failure (Baseline $\mathrm{pH}<7.35$ and $\mathrm{pCO} 2$ $>60 \mathrm{~mm} \mathrm{Hg}$ has been considered of either gender aged ranging from $40-80$ years were included in this study. Patients having tuberculosis (cough) at the time of admission, lung malignancy, bronchiectasis were excluded from this study. Demographic history [including age (in years) and sex (male or female) were taken. Arterial samples for arterial blood gases (ABG) were sent. Base line $\mathrm{pH}$ and $\mathrm{pcO} 2$ were measured. All the patients were offered with NIV for 12 hours. After 12 hours, ABG was again measured to see any improvement in $\mathrm{pH}$ and $\mathrm{pCO} 2$. Success as labeled as 'yes' if $\mathrm{pH}>7.35$ and $\mathrm{pCO} 2$ is $<60 \mathrm{~mm}$ of $\mathrm{Hg}$. The patients were discharged and follow up time was adjusted and data was analyzed by SPSS - 20. The categorical data like demographics (sex; male or female), Obesity $(\mathrm{BMl}>30)$ and success (yes or no) have been presented as frequency distribution. Quantitative data like age (in years), duration of disease, base line $\mathrm{pH}$ and $\mathrm{pCO} 2$, and 12 hours $\mathrm{pH}$ and $\mathrm{pCO} 2$ have been presented as means and standard deviations. The main outcome variable is success which has been presented as frequency and percentage. Age, gender, duration of disease and obesity $(\mathrm{BMI}>30)$ have been controlled through stratification applying Chi-square test. $\mathrm{P}$ value $\leq$ 0.05 was taken as significant.

\section{RESULTS}

Our study included 101 patients having type II respiratory failure due to acute exacerbation of chronic obstructive pulmonary disease. Of these 101 study cases, 53 (52.5\%) were male and 48 $(47.5 \%)$ were female patients having mean age 
$61.50 \pm 10.77$ years while 53 (52.5\%) belonged to age group of 60 to 80 years.

Mean duration of disease was $8.54 \pm 5.26$ years (Minimum disease duration was 2 years and maximum was 30 years). Mean BMl levels of our study cases was $23.31 \pm 2.18 \mathrm{Kg} / \mathrm{m}^{2}$ (with minimum BMI was $17 \mathrm{Kg} / \mathrm{m}^{2}$ while maximum BMI value was $28 \mathrm{Kg} / \mathrm{m}^{2}$ ).

Mean baseline $\mathrm{pH}$ value was $7.32 \pm 0.016$ (Minimum baseline $\mathrm{pH}$ was 7.29 while maximum baseline $\mathrm{pH}$ value was 7.34). Mean baseline $\mathrm{pCO}_{2}$ value was calculated to be $67.56 \pm 6.05 \mathrm{mmHg}$ (with minimum $\mathrm{pCO}_{2}$ level was 60 while maximum was $80 \mathrm{mmHg}$ ).

Mean $\mathrm{pH}$ value at 12 hours after NIV was $7.37 \pm$ 0.02 (Minimum pH was 7.33 while maximum pH value at 12 hours after NIV was 7.45). Mean $\mathrm{pCO}_{2}$ value at 12 hours after NIV was calculated to be $51.32 \pm 6.30 \mathrm{~mm} \mathrm{Hg}$ (with minimum $\mathrm{pCO}_{2}$ level was 40 while maximum was $76 \mathrm{mmHg}$ ).

Success was achieved in $98(97 \%)$ of our study cases while only in $03(3 \%)$ of our study cases could not attain desired results. Success was stratified with regards to gender, age, BMI and duration of disease and $p$ values calculated were found to be $p=1.00, p=0.591, p=0.026$ and $\mathrm{p}=0.606$ respectively.

\begin{tabular}{|c|c|c|c|}
\hline \multirow{2}{*}{$\begin{array}{c}\mathrm{BMI} \\
\left(\mathrm{In} \mathrm{Kg} / \mathrm{m}^{2}\right)\end{array}$} & \multicolumn{2}{|c|}{ Success } & \multirow[b]{2}{*}{ P-Value } \\
\hline & $\begin{array}{c}\text { Yes } \\
(n=98)\end{array}$ & $\begin{array}{c}\text { No } \\
(n=03)\end{array}$ & \\
\hline $\begin{array}{l}16-18.5 \\
(n=04)\end{array}$ & 03 & 01 & \multirow{4}{*}{0.026} \\
\hline $\begin{array}{l}18.6-25 \\
(n=81)\end{array}$ & 79 & 02 & \\
\hline $\begin{array}{l}25.1-30 \\
(n=16)\end{array}$ & 16 & Nil & \\
\hline Total & \multicolumn{2}{|c|}{101} & \\
\hline
\end{tabular}

Table-I. Stratification of success with regards to BMI $(n=101)$

\begin{tabular}{|c|c|c|c|}
\hline pH & Mean & $\begin{array}{c}\text { Standard } \\
\text { Deviation }\end{array}$ & P-Value \\
\hline Baseline value & 7.32 & 0.01 & 0.000 \\
\hline At 12 hours after NIV & 7.37 & 0.02 & 0.000 \\
\hline
\end{tabular}

Table-II. Comparison of baseline $\mathrm{pH}$ values with $\mathrm{pH}$ values at 12 hours after NIV $(n=101)$

\begin{tabular}{|c|c|c|c|}
\hline $\mathbf{p C O}_{2}$ & Mean & $\begin{array}{c}\text { Standard } \\
\text { Deviation }\end{array}$ & P-Value \\
\hline Baseline value & 67.56 & 6.05 & 0.000 \\
\hline At 12 hours after NIV & 51.32 & 6.30 & \\
\hline $\begin{array}{c}\text { Table-III. Comparison of baseline } \mathrm{pCO}_{2} \text { values with } \\
\mathrm{pCO}_{2} \text { values at 12 hours after } \mathrm{NIV}_{(\mathbf{n}=\mathbf{1 0 1})}\end{array}$ \\
\hline
\end{tabular}

\section{DISCUSSION}

For last couple of decades use of non-invasive ventilation (NIV) has gained much interest as there have been series of case reports, observational studies, systematic reviews and randomized controlled trials favoring this mode of treatment in acute care. ${ }^{11-15}$

The present study was conducted to document the success rate of NIV in our population presenting with acute respiratory failure due to acute exacerbation of chronic obstructive pulmonary disease.

One hundred and one, 53 (52.5\%) were male and $48(47.5 \%)$ were female. Pnadey et $\mathrm{al}^{10}$ reported $40 \%$ male patients and $60 \%$ female patients with type II respiratory failure in their study. Their findings are different from that of our study results.

Mean age of our study cases was $61.50 \pm 10.77$ years mean age $61.50 \pm 10.77$ years while 53 $(52.5 \%)$ belonged to age group of 60 to 80 years. Pnadey et $\mathrm{al}^{10}$ reported 66.5 years mean age of these patients in their study and also reported that majority of patients were in age range of 60 80 years of age. These findings are in compliance with that of our study results. Titles tad et $\mathrm{al}^{16}$ reported mean age of such patients 74 years which is bit high than that of our finding.

Mean baseline $\mathrm{pH}$ value was $7.32 \pm 0.016$ (Minimum baseline $\mathrm{pH}$ was 7.29 while maximum baseline $\mathrm{pH}$ value was 7.34). Mean baseline $\mathrm{pCO}_{2}$ value was calculated to be $67.56 \pm 6.05$ (with minimum $\mathrm{pCO}_{2}$ level was 60 while maximum was 80). Titlestad et $\mathrm{al}^{16}$ reported baseline $\mathrm{pH}$ value to be 7.26 , these findings are close to that of our study results.

Mean $\mathrm{pH}$ value at 12 hours after NIV was $7.37 \pm$ 0.02 (Minimum pH was 7.33 while maximum pH 
value was 7.45). Significant improvement was seen in our study cases in terms of their $\mathrm{pH}$ levels $(p=0.000)$. Budweiser et $\mathrm{al}^{17}$ reported mean $\mathrm{pH}$ 7.41 in their study, these study results are in compliance with that of our study results.

Mean $\mathrm{pCO}_{2}$ value at 12 hours after NIV was calculated to be $51.32 \pm 6.30 \mathrm{~mm} \mathrm{Hg}$ (with minimum $\mathrm{pCO}_{2}$ level was 40 while maximum was $76 \mathrm{~mm} \mathrm{Hg}$ ). Significant improvement was observed in $\mathrm{pCO}_{2}$ levels among our study cases after 12 hour NIV $(p=0.000)$. Thibout et $a^{18}$ reported mean $\mathrm{pCO}_{2}$ level to be $53 \pm 8 \mathrm{~mm} \mathrm{Hg}$, which is close to our study results.

Many randomized controlled trials have documented usefulness of NIV in different population subsets in patients with respiratory failure and COPD. ${ }^{10,15}$ Success was achieved in $98(97 \%)$ of our study cases while only in 03 (3\%) of our study cases could not attain desired results. Budweiser et al ${ }^{17}$ reported $88.9 \%$ success rate in their study, these findings are close to that of our study results. Pnadey et $\mathrm{al}^{10}$ reported $96.4 \%$ success rate in their study at 12 hours after NIV. Our study results are in compliance with that of those reported by Pnadey et al. ${ }^{10}$ Success rate was stratified with regards to gender, age, BMI and duration of disease and $p$ values calculated were found to be $p=1.00, p=0.591, p=0.026$ and $p=0.606$ respectively.

\section{CONCLUSION}

Our study results indicate that Non-invasive ventilation (NIV) is effective, reliable, safe and very cost effective method among the patients with respiratory failure due to acute exacerbation of COPD. Our study findings are in favor of current recommendations/guidelines regarding the use of NIV.

The patients with type II respiratory failure due to acute exacerbation of COPD benefited significantly with the use of NIV. Being a cost effective as well as safe mode of treatment, it may be employed in patients with type 2 respiratory failure due to COPD on priority basis. NIV is being employed currently in a various healthcare settings such as from the ICU to home care facilities. The appropriate selection of patients and the technical expertise of the health care staff and the patients to meet required adaptation to the procedure are of paramount importance for success of NIV. Being cost effective, it can add to the national health economies as well as beneficial for the sufferer families.

\section{Copyright $@ 25$ Nov, 2019.}

\section{REFERENCES}

1. Maclay JD, Rabinovich RA, MacNee W. Update in chronic obstructive pulmonary disease 2008. Am J Respir Crit Care Med 2009; 179:533-41.

2. Halbert RJ, Natoli JL, Gano A, Badamgarav E, Buist AS, Mannino DM. Global burden of COPD: systematic review and meta-analysis. Eur Respir J. Sep 2006; 28:523-32.

3. Quon BS, Gan WQ, Sin DD. Contemporary management of acute exacerbations of COPD: A systematic review and metaanalysis. Chest 2008; 133:756-66.

4. Ambrosino $\mathrm{N}$, Vagheggini $\mathrm{G}$. Non-invasive ventilation in exacerbations of COPD. Int $\mathrm{J}$ Chron Pulmon Dis 2007; 2:471-6.

5. Boldrini R, Fasano L, Nava S. Noninvasive mechanical ventilation. Curr Opin Crit Care 2012; 18:48-53.

6. Chawla R, Khilnani GC, Suri JC, Ramakrishnan N, Mani RK, Prayag S, et al. Guidelines for noninvasive ventilation in acute respiratory failure. Indian $\mathrm{J}$ Crit Care Med 2006; 10:117-47.

7. Nava S, Hill N. Non-invasive ventilation in acute respiratory failure. Lancet 2009; 374:250-59.

8. Keenan SP, Sinuff T, Burns KE, Muscedere J, Kutsogiannis J, Mehta S, et al. Clinical practice guidelines for the use of noninvasive positive-pressure ventilation and noninvasive continuous positive airway pressure in the acute care setting. CMAJ 2011; 183:195-214.

9. Bacakoglu F, Tasbakan MS, Basoglu OK, Öz T, Ürkmez $\mathrm{S}$, Midilli $\mathrm{M}$, et al. The factors affecting noninvasive mechanical ventilation failure in COPD exacerbations Turk J Med Sci 2012; 42:103-12.

10. Pnadey R, Chokhani R, N B KC. Use of non invasive ventilation in patients with respiratory failure in Nepal. Kathmandu Univ Med J (KUMJ), 2011 Oct-Dec; 9(36):256-9. 
11. Hensel M, Strunden MS, Tank S, Gagelmann N, Wirtz $\mathrm{S}$, Kerner T. Prehospital non-invasive ventilation in acute respiratory failure is justified even if the distance to hospital is short. Am J Emerg Med. 2019 Apr; 37(4):651-656.

12. Pandor A, Thokala P, Goodacre S, Poku E, Stevens JW, Ren S, et al. Pre-hospital non-invasive ventilation for acute respiratory failure: a systematic review and cost-effectiveness evaluation. Health Technol Assess. 2015 Jun; 19(42):v-vi, 1-102. doi: 10.3310/hta19420.

13. Faria DA, da Silva EM, Atallah ÁN, Vital FM. Noninvasive positive pressure ventilation for acute respiratory failure following upper abdominal surgery. Cochrane Database Syst Rev. 2015 Oct 5; (10):CD009134. doi: 10.1002/14651858.CD009134.pub2.

14. Osadnik CR, Tee VS, Carson-Chahhoud KV, Picot J, Wedzicha JA, Smith BJ. Non-invasive ventilation for the management of acute hypercapnic respiratory failure due to exacerbation of chronic obstructive pulmonary disease. Cochrane Database Syst Rev. 2017 Jul 13; 7:CD004104. doi: 10.1002/14651858. CD004104.pub4.
15. Kramer, N, Meyer, TJ, Meharg, J, Cece RD, Hill NS. Randomized, prospective trial of noninvasive positive pressure ventilation in acute respiratory failure. Am J Respir Crit Care Med. 1995; 151:17991806.

16. Titlestad IL, Lassen AT, Vestbo J. Long term survival for COPD patients receiving noninvasive ventilation for acute respiratory failure. Int J COPD. 2013; 8:21519.

17. Budweiser S, Hitzl AP, Jörres RA, Heinemann F, Arzt M, Schroll S, Pfeifer M. Impact of noninvasive home ventilation on long-term survival in chronic hypercapnic COPD: A prospective observational study. Int J Clin Pract. 2007; 61 (9):1516-22.

18. Thibout $\mathrm{Y}$, Philit F, Freymond $\mathrm{N}$, Petitjean $\mathrm{T}$, Nesme $\mathrm{P}$, Guerin C. Outcome in COPD patients treated with athome, long-term, non-invasive ventilation. Rev Mal Respir. 2006; 23:438-44.

\begin{tabular}{|c|c|c|c|}
\hline \multicolumn{4}{|c|}{ AUTHORSHIP AND CONTRIBUTION DECLARATION } \\
\hline Sr. \# & Author(s) Full Name & Contribution to the paper & Author(s) Signature \\
\hline 1 & M. Atiq ul Mannan & 1st Author & \\
\hline 2 & M. Imran Shahzad & 2nd Author & \\
\hline 3 & M. Waqas Afzal & 3rd Author & \\
\hline 4 & Humayoun Ghulam Murtaza & 4th Author & \\
\hline 5 & Muhammad Waseem & 5th Author & Waseem \\
\hline 6 & Tahir Khan & 6th Author & \\
\hline
\end{tabular}

